\title{
Perdas de água, solo e nutrientes por escoamento superficial após aplicação de dejetos líquidos de suínos na cultura do milho
}

\author{
June Faria Scherrer Menezes ${ }^{1}$, Mariana Pina da Silva ${ }^{2}$, Cleiton Gredson Sabin Benett ${ }^{2}$, \\ Vinicius de Melo Benites ${ }^{1}$, Veridiana Cardozo Gonçalves Cantão ${ }^{1}$ \\ ${ }^{1}$ Universidade de Rio Verde, Campus de Rio Verde, Goiás, Brasil. E mail: june@ unirv.edu.br, vinicius@cnps.embrapa.br, \\ veridiana@unirv.edu.br \\ ${ }^{2}$ Universidade Estadual de Goiás, Campus de Ipameri, Goiás, Brasil. E-mail: mariana.berti@ueg.br, cleiton.benett@gmail.com
}

Recebido: 09/06/2017; Aceito: 22/01/2018

\section{RESUMO}

O objetivo do trabalho foi avaliar a perda de solo, água e nutrientes em um Latossolo Vermelho distroférrico submetido a aplicação de dejetos líquido de suínos (DLS) e adubação mineral. O experimento foi conduzido em área experimental da Universidade de Rio Verde no período de outubro de 2005 a março de 2006 em área de sistema de plantio direto desde 2000. O experimento foi constituído por três tratamentos $\left(50 \mathrm{e} 200 \mathrm{~m}^{3} \mathrm{ha}^{-1}\right.$ de DLS e $570 \mathrm{~kg} \mathrm{ha}^{-1}$ da fórmula 04-14-08 (N-P $\left.\mathrm{P}_{2} \mathrm{O}_{5}-\mathrm{K}_{2} \mathrm{O}\right)$ para o cultivo de milho), estabelecidos em um delineamento experimental de blocos casualizados, com três repetições. O tratamento com a aplicação de $50 \mathrm{~m}^{3} \mathrm{ha}^{-1}$ de DLS resultou em maior perda de água e solo. Sendo que no tratamento com $200 \mathrm{~m}^{3} \mathrm{ha}^{-1}$ de DLS foi detectado menores perdas de água e solo por escoamento superficial. A produtividade do milho foi afetada pelos tratamentos. As perdas de solo foram muito baixas, muito aquém do valor de perdas de tolerância para esta classe de solo, apesar da tendência de maiores perdas apresentadas com $50 \mathrm{~m}^{3} \mathrm{ha}^{-1}$ de DLS. Entre os elementos químicos avaliados, o tratamento com $50 \mathrm{~m}^{3} \mathrm{ha}^{-1}$ apresentou perdas significativas de $\mathrm{N}$ e $\mathrm{Zn}$ quando comparado aos demais tratamentos.

Palavras-chave: Adubação orgânica, erosão, perda de nutrientes

\section{Losses of water, soil and nutrients by runoff after application of liquid swine manure in maize crop}

\begin{abstract}
To monitor the loss of soil, water and nutrients by runoff, from October 2005 to March 2006, in a Dystroferric Red Latosol, under no - tillage system since 2000, submitted to the application of liquid swine manure (LSM) and inorganic fertilizer, an experiment was conducted at the University of Rio Verde. The experiment consisted of three treatments (50 and $200 \mathrm{~m}^{3} \mathrm{ha}^{-1}$ of LSM and $570 \mathrm{~kg} \mathrm{ha}^{-1}$ of the formula 04-14-08 in maize crop), established in a randomized complete block design with three replications. Treatment with the application of $50 \mathrm{~m} 3 \mathrm{ha}-1$ of DLS resulted in greater loss of water and soil. Since the treatment with $200 \mathrm{~m}^{3} \mathrm{ha}^{-1}$ of DLS, lower losses of water and soil were detected by surface runoff. The productivity of grains was affected by treatments. Soil losses were very low, well below the tolerance losses for this class of soil, despite the trend of higher losses presented with 50 $\mathrm{m}^{3} \mathrm{ha}^{-1}$ of LSM. Among the evaluated chemical elements, the treatment with $50 \mathrm{~m}^{3} \mathrm{ha}^{-1}$ presented significant losses of $\mathrm{N}$ and $\mathrm{Zn}$ when compared to the other treatments.
\end{abstract}

Key words: erosion, organic fertilization, nutrient loss. 


\section{Introdução}

A cultura do milho, no Brasil, passa por importantes mudanças tecnológicas que tem resultado em aumento significativo da produtividade de grãos. Uma das tecnologias é o adequado manejo da fertilidade do solo que utiliza fertilizantes minerais e/ou orgânicos.

Os dejetos de suínos (DLS) consistem de uma mistura de fezes, urina e outros materiais orgânicos, como restos de alimentos, poeira, resíduos das baias e pelos de animais, além de uma quantidade variável de água desperdiçada pelos bebedouros e de higienização (GIACOMINI; AITA, 2008). Em busca do aumento de produtividade com redução de custos, a utilização do dejeto de suíno torna-se uma alternativa viável. Esses dejetos são caracterizados por serem um resíduo que contém teores elevados de matéria orgânica e nutrientes, principalmente nitrogênio e fósforo (SCHERER et al., 2010).

Embora a literatura internacional seja relativamente ampla sobre a utilização de dejetos de suínos como fertilizante e seu possível impacto ambiental, o acervo brasileiro é ainda bastante limitado. A maioria das informações restringe-se às curvas de resposta de algumas culturas, avaliando doses e fontes, normalmente, em experimentos de curta duração (KONZEN, 2000; SCHERER; NESI, 2007). Poucos são os trabalhos que apresentaram resultados do efeito cumulativo do uso prolongado de dejetos sobre características do solo, acúmulo de nutrientes no solo ou perda destes por escoamento superficial ou por lixiviação (SEDIYAMA et al., 2000; SCHERER et al., 2010; LOURENZI et al., 2014; SEDIYAMA et al., 2014; SOUSA et al., 2014).

$\mathrm{Na}$ cultura do milho, Seidel et al. (2010) demonstraram que a aplicação de DLS, em doses de até $50 \mathrm{~m}^{3} \mathrm{ha}^{-1}$, como adubação de base, não diferiu da adubação mineral (NPK). Trabalhando com a sucessão aveia/milho, Pinto et al. (2014) observaram que a utilização de DLS na dose de $80 \mathrm{~m}^{3} \mathrm{ha}^{-1}$ incrementou a produção de matéria seca e a produtividade de grãos.

Baseado neste contexto, o objetivo deste trabalho foi avaliar a perda de solo, água e nutrientes em um Latossolo Vermelho distroférrico submetido à aplicação de dejetos líquido de suínos e adubação mineral.

\section{Material e Métodos}

O experimento foi conduzido na Universidade de Rio Verde - Fesurv, localizada na latitude de $17^{\circ} 14^{\prime}$ 53 ' S, longitude de $50^{\circ} 55^{\prime} 14$ " W, altitude de $715 \mathrm{~m}$, clima Cf segundo Köppen, no município de Rio Verde $\mathrm{GO}$, em um Latossolo Vermelho distroférrico de textura argilosa com $4 \%$ de declividade. As principais propriedades do solo são mostradas na Tabela 1 .

No ano de 1999 foi instalado o sistema de monitoramento integrado da dinâmica de água e solutos no solo (SISDINA) (ANDRADE; ALVARENGA, 2000), para o estudo das perdas de nutrientes na água percolada e erodida, com a adubação das culturas com dejetos líquidos de suínos e adubo mineral. Após a instalação dos lisímetros, no primeiro ano (safra 2000/01), cultivou-se a área com soja, sendo que neste ano não foi feita nenhuma avaliação de dejetos. Após a colheita da soja, a área ficou em pousio. Na safra 2001/2002, foi implantada a cultura do milho; na safra 2002/2003, foi cultivado feijão; na safra 2003/2004, foi implantado milho e na entressafra, milheto; na safra 2004/2005, foi cultivado soja; na safra 2005/2006, foi cultivado milho.

O ensaio constou de três tratamentos de adubação, com três repetições, sendo as adubações constituídas de: 1) adubação com fertilizante mineral; 2) aplicação de 50 $\mathrm{m}^{3} \mathrm{ha}^{-1}$ de DLS; e, 3) aplicação de $200 \mathrm{~m}^{3} \mathrm{ha}^{-1}$ de DLS. A adubação mineral foi realizada conforme a necessidade da cultura que foi indicada pela análise de solo (Tabela 1) e expectativa de rendimento da cultura, segundo as recomendações de Sousa e Lobato (2004). Para este ano agrícola aplicou-se a dose de $570 \mathrm{~kg} \mathrm{ha}^{-1}$ da fórmula 04-14-08 mais $100 \mathrm{~kg} \mathrm{ha}^{-1}$ de $\mathrm{N}$ em cobertura aos 45 dias após plantio.

Os tratamentos com DLS foram aplicados na superfície do solo uma única vez, no dia 06 de outubro de 2005, 20 dias antes da semeadura do milho (híbrido Coodetec 308) que ocorreu no dia 26/10/2005. O tratamento com adubo mineral foi aplicado no sulco de plantio no momento da semeadura e a adubação nitrogenada de cobertura (ureia) foi realizada 45 dias após o plantio. Os DLS foram amostrados por ocasião da aplicação no solo e analisados quimicamente (Tabela 2).

Tabela1. Resultado da análise do solo (profundidade 0 a $20 \mathrm{~cm}$ ) coletada na área dos tratamentos com adubação mineral antes da semeadura do milho e aplicações dos tratamentos. Safra 2005/2006

\begin{tabular}{|c|c|c|c|c|c|c|}
\hline $\mathrm{Ca}$ & $\mathrm{Mg}$ & K & $\mathrm{Al}$ & $\mathrm{H}+\mathrm{AL}$ & CTC & V \\
\hline - & ---- & ----- c & & & ---- & $\%$ \\
\hline 1,6 & 0,51 & 0,32 & 0,08 & 2,82 & 5,47 & 48,6 \\
\hline $\mathrm{pH}$ & $\mathrm{MO}$ & Argila & $\mathrm{P}$ & $\mathrm{K}$ & $\mathrm{Cu}$ & $\mathrm{Zn}$ \\
\hline $\mathrm{CaCl}_{2}$ & ------- & --------- & --- & - & ----- & --- \\
\hline 5,14 & 10,4 & 570 & 1,06 & 126 & 3,8 & 2,08 \\
\hline
\end{tabular}


Tabela 2. Teores de $\mathrm{N}, \mathrm{P}_{2} \mathrm{O}_{5}$ e $\mathrm{K}_{2} \mathrm{O}\left(\mathrm{kg} \mathrm{ha}^{-1}\right)$ em função dos tratamentos

\begin{tabular}{cccccc}
\hline Tratamentos & $\mathrm{N}$ & $\mathrm{P}_{2} \mathrm{O}_{5}$ & $\mathrm{~K}_{2} \mathrm{O}$ & $\mathrm{Cu}$ & $\mathrm{Zn}$ \\
\hline $50 \mathrm{~m}^{3} \mathrm{ha}^{-1}$ DLS & $30^{1 /}$ & $5^{2 /}$ & $60^{3 /}$ & 362,5 & 357,5 \\
$200 \mathrm{~m}^{3} \mathrm{ha}^{-1}$ DLS & 120 & 20 & 240 & 1450 & 1430 \\
Químico & $22,8+100$ & 80 & 46 & - & - \\
\hline
\end{tabular}

${ }^{1} \mathrm{~N}$ total $=0,6 \mathrm{~kg} \mathrm{~m}^{-3} ;{ }^{2 /} \mathrm{P} 2 \mathrm{O} 5=0,1 \mathrm{~kg} \mathrm{~m}^{-3} ;{ }^{3 /} \mathrm{K}_{2} \mathrm{O}=1,2 \mathrm{~kg} \mathrm{~m}^{-3}$ (baseado na análise química dos DLS)

Durante o período de condução do experimento foram avaliadas as perdas de solo e água por escoamento superficial, em função de cada tratamento e principalmente dos índices pluviométricos ocorridos no período. Foram feitas oito coletas, durante a safra, nos dias 19 de novembro de 2005, 2 de dezembro de 2005, 10 de dezembro de 2005, 12 de dezembro de 2005, 26 de dezembro de 2005, 14 de janeiro de 2006, 15 de fevereiro de 2006 e finalizando no dia 17 de março de 2006.

A medição do volume de enxurrada foi realizada em reservatórios de armazenamento (Figura 1) com auxílio de uma régua graduada de $50 \mathrm{~cm}$ em que, após calibração, obteve-se o valor de cada centímetro correspondente a oito litros de água. Nesse reservatório foi coletada uma amostra de $60 \mathrm{~mL}$ do sobrenadante e em seguida aplicou-se para cada oito litros de água, dois gramas de sulfato de alumínio $\left(\left(\mathrm{Al}_{2} \mathrm{SO}_{4}\right)_{2} \cdot 12 \mathrm{H}_{2} \mathrm{O}\right)$ com o objetivo de promover a decantação do solo em suspensão no reservatório, para separar o solo da água.

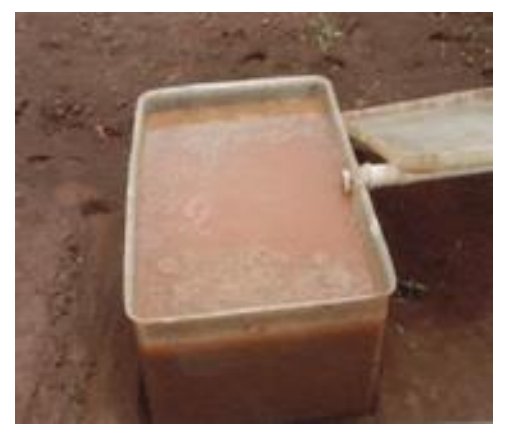

Figura 1. Reservatório de armazenamento da água e solo perdidos por escoamento superficial.

Para completa decantação do solo foram necessárias 24 horas; posteriormente foi realizada a drenagem dos reservatórios utilizando-se mangueira comum e medida a quantidade de solo perdido por tratamento. As amostras de solo decantadas foram colocadas em latas de alumínio, secas em estufa a $105^{\circ} \mathrm{C}$ por 48 horas e pesadas em balança de precisão para determinar o peso seco desse solo, então foram levadas ao laboratório para determinação dos macronutrientes $\mathrm{N}, \mathrm{P}$ e $\mathrm{K}$ e dos micronutrientes $\mathrm{Cu}$ e $\mathrm{Zn}$. As amostras do sobrenadante também foram levadas ao laboratório para determinação de $\mathrm{N}, \mathrm{P}, \mathrm{K}, \mathrm{Cu}$ e $\mathrm{Zn}$ contidos na água de enxurrada, segundo metodologia descrita por Silva (1999).
A colheita foi realizada no dia 21/03/06, e os grãos foram pesados e posteriormente calculadas as produtividades em $\mathrm{kg} \mathrm{ha}^{-1}$, sendo a umidade dos grãos ajustada para $13 \%$. Os resultados foram submetidos à análise de variância e as médias comparadas pelo teste de Tukey, a 5\% de probabilidade, utilizando-se o programa SAEG (RIBEIRO-JÚNIOR, 2001).

\section{Resultados e Discussão}

A distribuição da precipitação pluviométrica (Figura 2) durante a condução do experimento foi favorável para a cultura do milho, não afetando negativamente no desenvolvimento e produtividade de grãos (Figura 3). Cerca de $50 \%$ do volume total de chuvas ocorreu entre a segunda quinzena de novembro até o final do mês de dezembro (Figura 2), perfazendo $6556 \mathrm{~m}^{3}$.

A maior produtividade foi obtida com a adubação mineral quando comparado com as aplicações dos DLS. Deve-se salientar que a adubação mineral é baseada nas necessidades da cultura e os nutrientes adicionados são prontamente disponíveis para a planta, enquanto que as aplicações de DLS devem passar pelo processo de mineralização para que o mesmo ocorra. Este fator pode ter influenciado na produtividade dos tratamentos com DLS visto que foram estes que obtiveram menor produtividade (Figura 3).

As perdas da água por escoamento superficial (Figura 4), medidas quinzenalmente, caracterizaram-se baixas em todos os tratamentos, quando comparados com a precipitação ocorrida na área (Figura 2), sendo que a maior parte da água da chuva infiltrou no solo. A infiltração foi favorecida por se utilizar o sistema plantio direto, em que a superfície do solo foi mantida com palha durante a safra, além de proporcionar maior estabilidade de estrutura e agregação do solo (ALBUQUERQUE et al., 2001).

No início do desenvolvimento do milho, nos meses de novembro e dezembro, houve pouca absorção de água pela planta, e grandes perdas por escoamento superficial ou infiltração de água no solo. Nesta época as intensidades pluviométricas foram altas, cerca de $7200 \mathrm{~m}^{3}$. Em janeiro e fevereiro, menores perdas de água ocorreram em função de baixas taxas de precipitação e maior consumo de água pela planta, pois a cultura estava em pleno estádio vegetativo (Figura 4). 


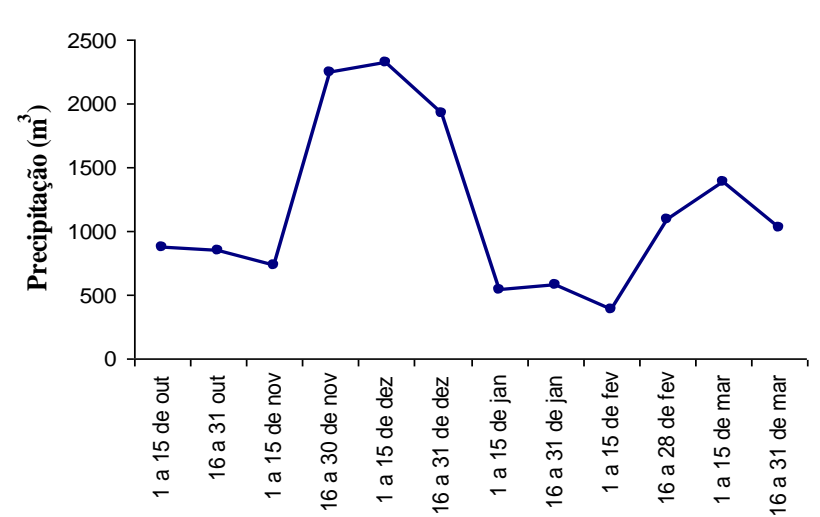

Figura 2. Precipitação ocorrida durante o período de cultivo de milho, safra 2005/06, adubado com dejetos de suínos e adubo mineral.

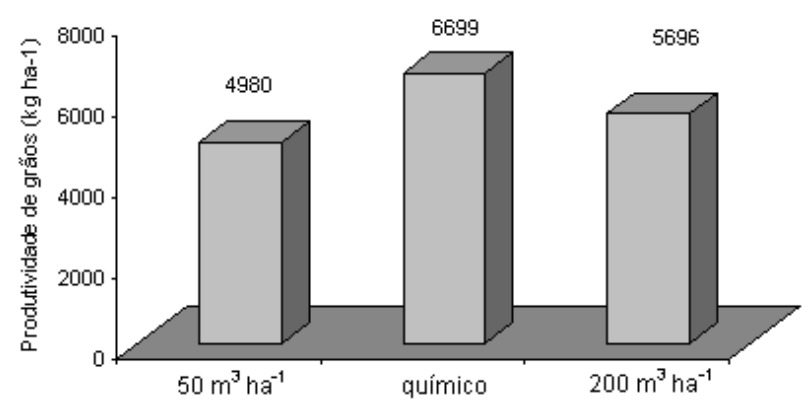

Figura 3. Produtividade do milho, adubado com $50 \mathrm{~m}^{3} \mathrm{ha}^{-1} \mathrm{e}$ $200 \mathrm{~m}^{3} \mathrm{ha}^{-1}$ dejetos de suínos e adubo mineral.

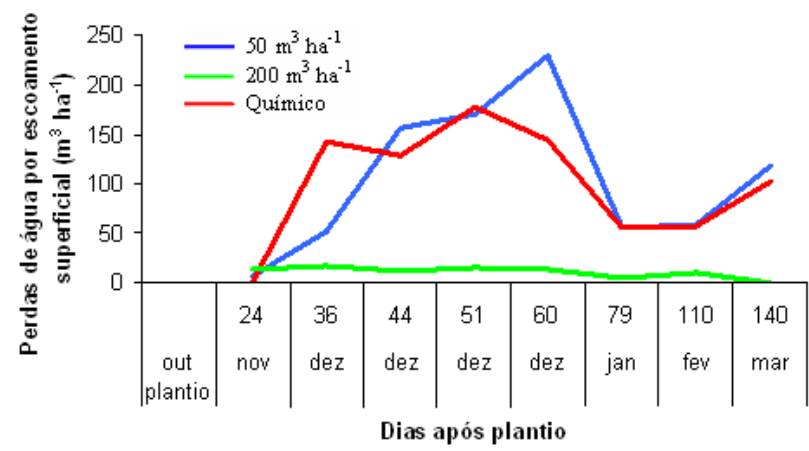

Figura 4. Perdas de água por escoamento superficial durante o período de cultivo de milho, safra 2005/06, em função da aplicação de 50 e $200 \mathrm{~m}^{3} \mathrm{ha}^{-1}$ de dejetos de suínos e adubação química.

O consumo de água pela cultura do milho é de aproximadamente três milímetros por dia $(3 \mathrm{~mm}) \mathrm{em}$ um clima quente (tropical) considerando uma planta com altura inferior a trinta centímetros, entretanto, durante o período compreendido entre o espigamento e a maturação, o consumo de água pode se elevar para cinco a sete milímetros diários, favorecendo o processo de infiltração (FANCELLI; DOURADO NETO, 2000).

Em novembro a precipitação foi de $2970 \mathrm{~m}^{3}$, sendo que nos dias antecedentes à coleta houve uma precipitação de $52,1 \mathrm{~mm}$, caracterizando assim, o início das perdas de água e solo por escoamento superficial. $\mathrm{O}$ mês de dezembro caracterizou-se pela maior intensidade pluviométrica, equivalendo a um total de $4237 \mathrm{~m}^{3}$, sendo o mês que apresentou as maiores perdas de água (Figuras 4).

No mês de Janeiro houve redução na precipitação local, considerado o mês de menor intensidade pluviométrica $\left(1109 \mathrm{~m}^{3}\right)$, apresentou também menores perdas de água, confirmando assim os resultados obtidos. Em fevereiro a precipitação foi de $2073 \mathrm{~m}^{3}$ caracterizando aumento nas perdas de água por escoamento superficial quando comparado com o mês de janeiro. Em março, realizou-se a última coleta, na qual observaram-se maiores perdas no tratamento com fertilizante mineral e com aplicação de $50 \mathrm{~m}^{3} \mathrm{ha}^{-1}$ de DLS (Figuras 4), pois nos dias antecedentes à coleta houve intensas precipitações representando $43 \%$ da precipitação total do mês que foi de $2411 \mathrm{~m}^{3}$.

$\mathrm{O}$ tratamento referente à adubação com $200 \mathrm{~m}^{3} \mathrm{ha}^{-1}$ de dejetos líquidos de suínos apresentou as menores perdas de água quando comparada com os demais tratamentos, com a maior perda aos 36 dias após semeadura, referente às precipitações acumuladas do dia 20 de novembro ao dia 1 de dezembro equivalendo a um total de $1732 \mathrm{~m}^{3}$ (Figura 2).

As maiores perdas de água por escoamento superficial ocorreram com o tratamento de $50 \mathrm{~m}^{3} \mathrm{ha}^{-1} \mathrm{de}$ DLS, quando comparado à aplicação de $200 \mathrm{~m}^{3} \mathrm{ha}^{-1} \mathrm{de}$ DLS, pois não diferenciou estatisticamente do tratamento mineral. As perdas de água corresponderam a $6,1 \%, 0,63 \%$ e $5,8 \%$ da precipitação total, respectivamente, para $50 \mathrm{~m}^{3} \mathrm{ha}^{-1}$ de DLS, $200 \mathrm{~m}^{3} \mathrm{ha}^{-1} \mathrm{de}$ DLS e fertilizante mineral (Figuras 5 e 6 ).

Observou-se durante o experimento que o tratamento com $50 \mathrm{~m}^{3} \mathrm{ha}^{-1}$ de DLS foi o que apresentou menor formação de palhada e, consequentemente, menor cobertura do solo, fato que provavelmente contribuiu para as maiores perdas de água neste tratamento. Apesar do tratamento de $50 \mathrm{~m}^{3} \mathrm{ha}^{-1}$ de DLS ter apresentado as maiores perdas, não diferiu estatisticamente do tratamento com fertilizante mineral (Figura 6).

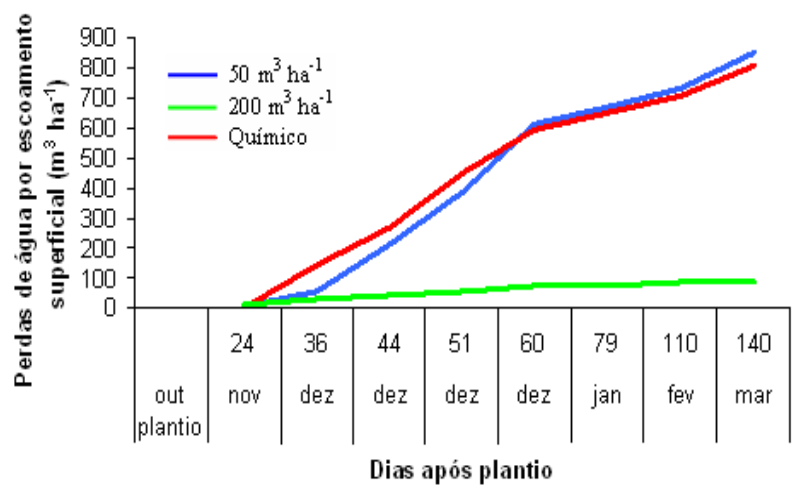

Figura 5. Perdas de água acumulada por escoamento superficial durante o período de cultivo de milho, em função da aplicação de 50 e $200 \mathrm{~m}^{3}$ ha $^{-1}$ de DLS e adubação química. 


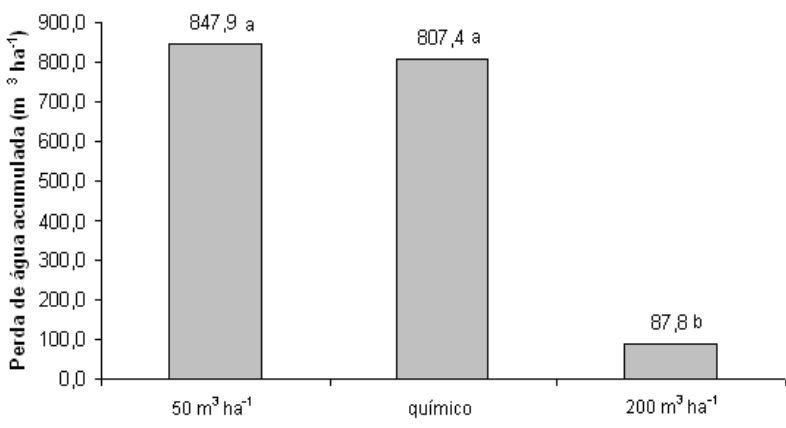

Figura 6. Perda total de água acumulada por escoamento superficial durante o período de cultivo de milho, safra 2005/06, em função da aplicação de 50 e $200 \mathrm{~m}^{3} \mathrm{ha}^{-1} \mathrm{de}$ dejetos de suínos e adubação química. Médias seguidas pela mesma letra não diferem estatisticamente pelo teste de Tukey a 5\% de significância.

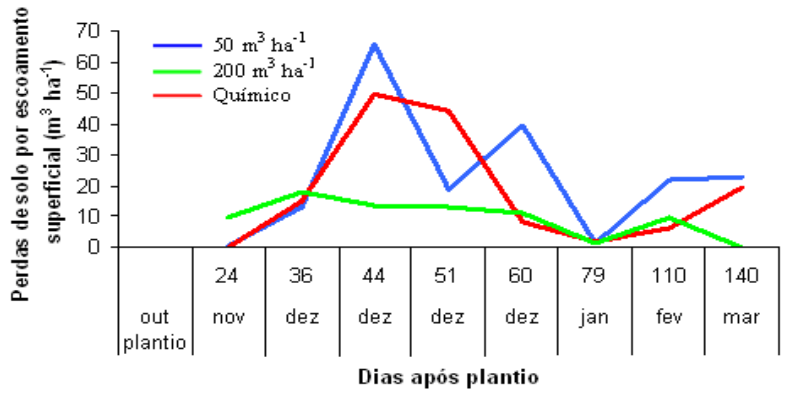

Figura 7. Perdas de solo por escoamento superficial durante o período de cultivo de milho, safra 2005/06, em função da aplicação de 50 e $200 \mathrm{~m}^{3}$ há ${ }^{-1}$ de dejetos líquidos de suíno e de adubação química.

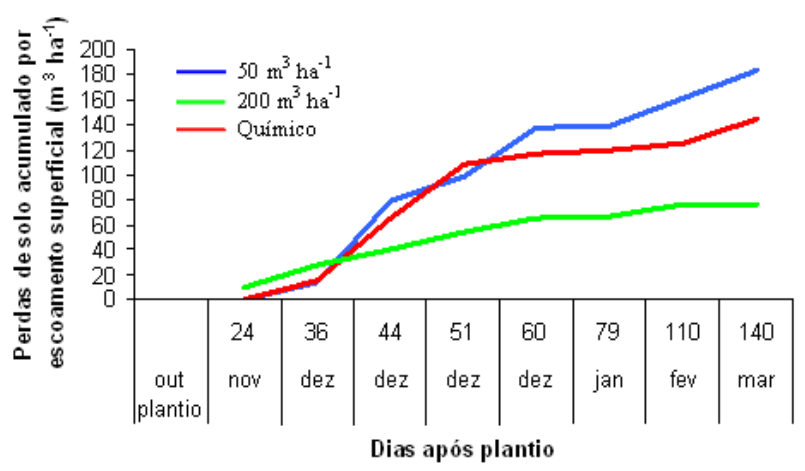

Figura 8. Perdas de solo acumulado por escoamento superficial durante o período de cultivo de milho, safra 2005/06, em função da aplicação de 50 e $200 \mathrm{~m}^{3}$ há $^{-1}$ de dejetos líquidos de suíno e de adubação química.
As maiores perdas de solo ocorreram no tratamento de $50 \mathrm{~m}^{3} \mathrm{ha}^{-1}$ de DLS, especialmente entre 36 a 51 dias após o plantio, o que coincide com a maior incidência de precipitação, correspondendo a um total de $2491 \mathrm{~m}^{3}$. A partir dos 60 dias após plantio, houve uma redução com relação à perda de solo, mesmo observando-se chuvas de 18,9 a 29,3 mm. Entretanto, houve pico de perdas de solo próximo ao fim do ciclo da cultura, em consequência do aumento da intensidade pluviométrica (Figura 2) com chuvas de elevada intensidade até o fim das avaliações experimentais quando a cultura já apresentava maturação fisiológica e pouca atividade radicular. A reduzida presença de palhada no solo em consequência da sua decomposição pode também ter influenciado no aumento das perdas.

O tratamento com a aplicação de $200 \mathrm{~m}^{3} \mathrm{ha}^{-1}$ de DLS foi o que apresentou menor perda de solo comparado aos demais tratamentos, entretanto, apresentou maior perda de solo aos 36 dias após a semeadura, o que confirma os resultados obtidos para perda de água por escoamento superficial (Figuras 4).

Avaliando-se os teores de nutrientes no sedimento de solo coletado, verificou-se maiores quantidades de $\mathrm{N}$ e $\mathrm{Zn}$ para o tratamento $50 \mathrm{~m}^{3} \mathrm{ha}^{-1}$ e menor com tratamento mineral. $\mathrm{O}$ tratamento mineral também apresentou menor teor de $\mathrm{P}$, sendo que para os teores de $\mathrm{K}$ não houve diferença significativa entre os tratamentos. $\mathrm{O} \mathrm{Cu}$, tratamento com $200 \mathrm{~m}^{3} \mathrm{ha}^{-1}$ foi o que apresentou menor teor no sedimento perdido por escorrimento superficial.

Pelos resultados dos teores de nutrientes no solo, verificou-se alto potencial poluidor causado pelas adubações, principalmente com a aplicação de $50 \mathrm{~m}^{3} \mathrm{ha}^{-}$ 1 DLS (Tabela 3). Apesar de possuir menores quantidades de nutrientes em relação à aplicação de 200 $\mathrm{m}^{3} \mathrm{ha}^{-1}$ DLS, valores absolutos (Tabela 2), os teores foram maiores no solo devido a menor absorção destes nutrientes pelas plantas, provavelmente deficientes nutricionalmente, principalmente em $\mathrm{N}$ e P. Quanto mais vigorosa a planta maior o sistema radicular e maior a quantidade de nutrientes absorvidos (MALAVOLTA et al.,1997).

Tabela 3. Teores de N, P, K, Cu e Zn $\left(\mathrm{g} \mathrm{kg}^{-1}\right)$ no solo perdido por escoamento superficial.

\begin{tabular}{|c|c|c|c|c|c|}
\hline Tratamentos & $\mathrm{N}$ & $\mathrm{P}$ & $\mathrm{K}$ & $\mathrm{Cu}$ & $\mathrm{Zn}$ \\
\hline & & & $-\mathrm{g} \mathrm{kg}^{-1}-$ & & \\
\hline $50 \mathrm{~m}^{3} \mathrm{ha}^{-1} \mathrm{DLS}$ & $1,6 \mathrm{a}$ & $245,14 \mathrm{a}$ & $256,81 \mathrm{a}$ & $15,36 \mathrm{a}$ & $140,79 \mathrm{a}$ \\
\hline $200 \mathrm{~m}^{3} \mathrm{ha}^{-1}$ DLS & $0,8 \mathrm{~b}$ & $201,96 \mathrm{a}$ & $242,85 \mathrm{a}$ & $4,19 \mathrm{~b}$ & $40,63 \mathrm{~b}$ \\
\hline Adubação mineral & $0,12 \mathrm{c}$ & $65,08 \mathrm{~b}$ & $141,45 \mathrm{a}$ & $11,79 \mathrm{a}$ & $79,51 \mathrm{~b}$ \\
\hline
\end{tabular}

Mesmas letras minúsculas na coluna não diferem estatisticamente pelo teste de Tukey a 5\% de significância. 
Avaliando-se as perdas de nutrientes por hectare, levando-se em consideração as perdas totais de solo, observou-se que foram insignificantes os conteúdos destes nutrientes avaliados (Figura 10). Dentre os macronutrientes avaliados, o nitrogênio foi o que apresentou maior perda nos três tratamentos em relação aos demais nutrientes. Com relação aos micronutrientes, o $\mathrm{Cu}$ apresentou menores perdas quando comparado com o $\mathrm{Zn}$.

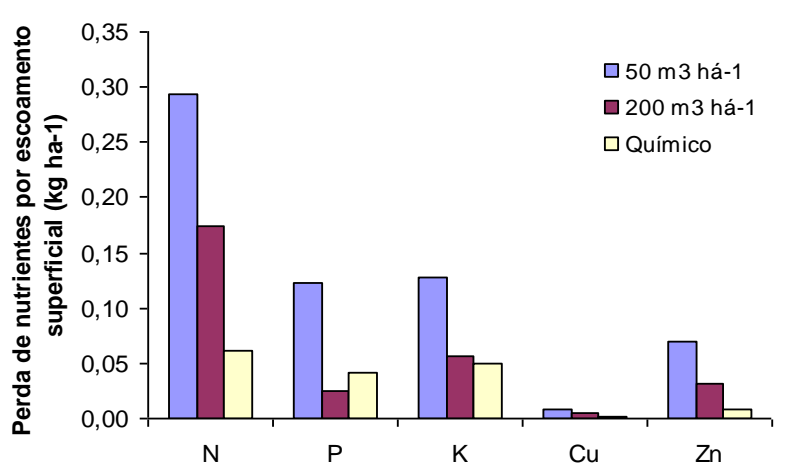

Figura 10. Perda de nutrientes por escoamento superficial durante o período de cultivo de milho, safra 2005/06, em função da aplicação de 50 e $200 \mathrm{~m}^{3}$ há ${ }^{-1}$ de dejetos líquidos de suíno e de adubação química.

\section{Conclusões}

A aplicação de $200 \mathrm{~m}^{3}$ ha $^{-1}$ de DLS apresentou menor perda de água, solo e nutrientes por escoamento superficial.

A aplicação de $50 \mathrm{~m}^{3} \mathrm{ha}^{-1}$ de DLS aumentou as perdas por escoamento superficial de água e solo.

As perdas de solo foram consideradas muito baixas, atingindo níveis desejáveis quanto à tolerância de perdas de solo, apesar da tendência de maiores perdas apresentadas com a aplicação de $50 \mathrm{~m}^{3} \mathrm{ha}^{-1}$ de DLS.

As maiores perdas de nutrientes ocorreram com a aplicação de $50 \mathrm{~m}^{3} \mathrm{ha}^{-1}$, principalmente para $\mathrm{N}$ e $\mathrm{K}$.

\section{Referências Bibliográficas}

ALBUQUERQUE, J. A.; SANGOI, L.; ENDER, M. Efeitos da integração lavoura-pecuária nas propriedades físicas do solo e características da cultura de milho. Revista Brasileira de Ciência do Solo, Viçosa-MG, v. 25, n. 3, p. 717-723, 2001.

BERTONI, J.; LOMBARDI NETO, F. Conservação do solo. 4. ed. São Paulo-SP: Ícone, 1999. 355 p.

FANCELlI, A. L.; DOURADO NETO, D. Produção de milho. Guaíba-SP: Editora Agropecuária, 2000, 360 p.

GIACOMINI, S. J.; AITA, C. Cama sobreposta e dejetos líquidos de suínos como fonte de nitrogênio ao milho. Revista Brasileira de Ciência do Solo, Viçosa-MG, v. 32, n. 1, p. 195-205, 2008.
KONZEN, E.A. Alternativas de manejo, tratamento e utilização de dejetos animais em sistemas integrados de produção. Sete Lagoas-MG: Embrapa Milho e Sorgo, 2000. 32 p. (Documentos, 5).

LOURENZI, C. L.; CERETTA, C. A.; BRUNETTO, G.; GIROTTO, E.; TIECHER, T. L.; VIEIRA, R. C. B.; CANCIAN, A.; FERREIRA, P. A. A. Pig slurry and nutrient accumulation and dry matter and grain yield in various crops. Revista Brasileira de Ciência do Solo, Viçosa-MG, v. 38, n. 3, p. 949-958, 2014.

MALAVOLTA, E.; VITTI, G. C.; OLIVEIRA, S. A. Avaliação do estado nutricional das plantas: princípios e aplicações. Piracicaba-SP: POTAFOS, 1997. 201 p.

RIBEIRO JUNIOR, J. I. Análises estatísticas no SAEG (Sistema para análises estatísticas). Viçosa-MG: Universidade Federal de Viçosa, 2001. 301 p.

SCHERER, E. E.; NESI, C. N. Sistemas de preparo do solo, doses e fontes de adubo nitrogenado na produtividade de milho. Agropecuária Catarinense, Florianópolis-SC, v. 20, n. 2, p. 67-71, 2007.

SCHERER, E. E.; NESI, C. N.; MASSOTTI, Z. Atributos químicos do solo influenciados por sucessivas aplicações de dejetos suínos em áreas agrícolas de Santa Catarina. Revista Brasileira Ciências Solo, Viçosa-MG, v. 34, n. 4, p. 13751383,2010

SEDIYAMA, M. A. N.; GARCIA, N. C. P.; VIDIGAL, S. M.; MATOS, A. T. Nutrientes em compostos orgânicos de resíduos vegetais e dejeto de suínos. Scientia Agrícola, Piracicaba-SP, v. 57, n. 1 p. 185-189, 2000.

SEDIYAMA, M. A. N.; SANTOS, M. R.; VIDIGAL, S. M.; PINTO, C. L. O.; JACOB, L. L. Nutrição e produtividade de plantas de pimentão colorido, adubadas com biofertilizante de suíno. Revista Brasileira de Engenharia Agrícola e Ambiental, Campina Grande-PB, v. 18, n. 6, p. 588-594, 2014.

SEIDEL, E. P.; GONÇALVES JUNIOR, A. C.; VANIN, J. P.; STREY, L.; SCHWANTES, D.; NACKE, H. Aplicação de dejetos de suínos na cultura do milho cultivado em sistema plantio direto. Acta Scientiarum Tecnology, Maringá-PR, v. 32, n. 2, p. 113-117, 2010.

SILVA, F. C. Manual de análises químicas de solos, plantas e fertilizantes. Brasília-DF: Embrapa Solos, 1999. 370 p.

SOUSA, D. M. G.; LOBATO, E. Cerrado: Correção do solo e adubação. 2. ed. Brasília-DF: Embrapa Solos Informação Tecnológica, 2004. 416 p.

SOUSA, F. A.; SILVA, E. B.; CAMPOS, A. T.; GANDINI, A. M. M.; CORRÊA, J. M.; GRAZZIOTTI, P. H. Atividade microbiana e produção da lavoura cafeeira após adubação com dejetos líquidos de suínos. Bioscience Journal, UberlandiaMG, v. 30, n. 4, p. 1041-1049, 2014.

PINTO, M. A.; FABBRIS, C.; BASSO, C. J.; SANTI, A. L.; GIROTTO, E. Aplicação de dejeto líquido de suínos e manejo do solo na sucessão aveia/milho. Pesquisa Agropecuária Tropical, Goiânia-GO, v. 44, n. 2, p. 205-212, 2014. 